\title{
Effect of Critical Dialogue on Students' Academic Performance in Economics in Abeokuta, Nigeria
}

Adesegun O. Odutayo

University of Ilorin, Nigeria, o_odutayo@yahoo.com

Hamdallat Taiwo Yusuf

PhD., University of Ilorin, Nigeria, hamdallatyusuf@unilorin.edu.ng

Critical dialogue is a problem-posing discussion set up to ensure equal access and participation by all students, constructed to focus on a multiplicity of viewpoints. This study examined the effects of Critical Dialogue on the academic performance of students in Economics in Abeokuta, Ogun State, Nigeria. Quasi-Experimental design was adopted. Two research questions were raised for this study which had corresponding hypotheses. 73 students (35 critical dialogue and 38 conventional) were randomly selected from a purposefully sampled secondary school. ANCOVA was used to the hypotheses generated. There was significant difference in the performance of students exposed to critical dialogue. This study recommended among others that teachers should expose students to critical dialogue instructional strategies to develop students' generic skills.

Keywords: effect, critical dialogue, academic performance, scoring level, economics

\section{INTRODUCTION}

Humans have always been differentiated from the rest of the animal kingdom because of their ability to coordinate and organize their effort towards a common purpose which has also been responsible for many of humanity's greatest achievements (Stauffer, 2013). Students could greatly benefit by playing the role of the teacher, this is believed by the famous Moravian educator, Comenius. Stauffer (2013) stated that critical dialogue instructional strategy is similar to the art of discourse, where students are taught through dialogue and discussion. Van Myk (2007) stated that in the perspective of constructivism, the primary responsibility of a teacher is to create and maintain a problem-solving environment where learners are allowed to construct their knowledge and the teacher acts a facilitator and guide. Vygotsky's theory of social constructivism, as opposed to Piaget's individualistic approach to constructivism, emphasized learners' interaction with others in terms of cognitive development.

Teachers can enhance learners' development by presenting tasks that is, within each learner's zone of proximal development (i.e. the difference between what a learner can do without help and what he or she can do with help) (Ormrod, 1995). This can be achieved through students' dialogue with the teachers and also with one another (Van Myk, 2007). The conventional method of teaching (lecture method) is not practical, more theoretical and encourages memorization by students (Teo \& Wong, 2000). Students are not encouraged to apply activity-based learning to understand real-life problems based on applied knowledge when they are taught with lecture method. Since the teacher controls the transmission and sharing of knowledge, an attempt might be made by the lecturer to maximize the delivery of information, while minimizing time and effort. Therefore, students' interest and understanding may be found wanting.

Citation: Odutayo, A. O. \& Yusuf, H. T. (2020). Effect of Critical Dialogue on Students' Academic Performance in Economics in Abeokuta, Nigeria. Anatolian Journal of Education, 5(2), 85-94. https://doi.org/10.29333/aje.2020.527a 
To address these, Zakaria, Chin and Daud (2010) opined that for effective and efficient teaching and learning, acquisition of knowledge should not merely focus on dispensing rules, definitions and procedures for students to memorize, but should be inclined to actively engage students as primary participants. As a result of innovations in the concept of discovery learning, different scholars have adopted more appropriate student-centred strategies to enhance active learning (Greitzer, 2002). Some of these strategies are; Role play, discussion, demonstration, field trip, critical dialogue, peer tutoring etc. It is of interest to the researcher to ascertain whether critical dialogue could be used in teaching economics.

Freire (2003) explained that dialogue is a situation in which both, students and teachers exchange roles and learn from and with each other. Mejia (2004) is of the opinion that humility and faith represent conditions that clearly distinguish a dialogue from a conversation. This is seen as openness to other people's perspectives which is embedded in the belief, or internalized faith, that others are capable of drawing their conclusions and readings of situations. Also, a condition for a dialogical exchange is the hope that positive change will occur. It is man's incompletion or unfinished nature that lay the foundation for the world of possibilities encouraged by dialogue (Freire, 2007). Leistyna (2009) submitted that dialogue must motivate students and teachers to expand and critically explore what they know. Dialogue is beyond a simple process of turn-taking and mechanical back-and-forth. Critical dialogue is a problem-posing discussion set up to ensure equal access and participation by all members, constructed to focus on a multiplicity of viewpoints, and designed to bring awareness to social and historical power imbalances to promote action (Kincheloe, 2007).

Johnson and Morris (2010) explained that through critical dialogue, students learn from one another, thereby giving way to critical pedagogues to counteract more typical individualistic and competitive approaches to education. Critical dialogue is the ongoing collective inquiry into the processes, assumptions, and certainties that comprise everyday life (Schein, 1993). Critical dialogue is a liaison act in which peers assist each other in the mutual examination of biases. This collaboration is necessary because assumptions and biases are too easily overlooked in solitary reflection, especially when applied to situations where race, ethnicity, or economic status, privilege one group over another. Critical dialogue requires the awareness of the ways personal biases can influence thinking, understanding language as a tool for learning rather than the only expression of ideas. Also, it requires specific skills in speaking and listening to promote mutual learning. These are not skills with which most people are naturally gifted or ones they use in much of their normal discourse. Critical dialogue is a process that can be learned, but it must be taught and practised. Mezirow (2000) suggested that critical dialogue has a long history in adult education, and it takes many forms.

The use of dialogue for transformative thinking and practice can be traced to Freire (1990), who combined meaningful changes in thinking with an awareness of social contexts and the call for political action. Dialogue can be used as a tool for change and has also taken root in industrial organization (Isaacs, 2001) and consistently, in education (Takeda, Marchel, \& Gaddis, 2002). Critical dialogue has been traced to action research, especially where multiple stakeholders come together to work on shared problems and evidence-informed practice (Moyles, Adams, \& Musgrove, 2002). Critical dialogue goes beyond simple self-reflection because it allows peer interactions and provides scaffolds that support and guide reflection. Additionally, dialogic pedagogy distances itself from traditional teaching through the openings it provides to analyze competing definitions of similar issues (Duncum, 2008). Jackson (2008) explained that by placing teachers and students in positions of agency, dialogic education transforms traditional lessons into democratic educational experiences.

There are many distinct types of dialogue. Each is governed by different goals and by different kinds of procedural rules that facilitate getting to the goal from an initial situation. Some types of dialogue are more adversarial than others and the procedural rules are stated clearly and are stricter in some

Anatolian Journal of Education, October $2020 \bullet$ Vol.5, No.2 
contexts of dialogue than in others. For example, the criminal trial is a kind of dialogue where the rules of procedure are stated clearly and are often strictly upheld, even though they typically require interpretation by a judge (Barth \& Krabhe, 1998). The parliamentary debate is also adversarial, and rules of arguing are stated clearly, but these rules are less elaborate, less strict, and more loosely enforced in most instances.

The goal of a dialogue can be to reach an agreement, to carry out an action, to transfer knowledge from one party to another, or to defeat one's opponent by any means. The realization of each of these types of goals involves a different type of dialogue. Besides, many types of dialogues can have subtypes. In some situations, the rules that define the goals and permissible moves in a dialogue are codified and institutionalized so that by entering into dialogue the students, in effect, bind themselves to the rules. In other situations, no strict rules may be stated or accepted before the beginning of a discussion, and it may be left to the students to articulate or propose rules to facilitate the goals of the dialogue.

Dispute dialogue is comprised of two arguers. The thesis to be proved by one student is the opposite (negation) of the thesis to be proved by the other student. In a dispute, this pair of propositions to be proved by the opposing sides is the issue of the dialogue. Although, not all dialogues are disputes. Characteristically, the dispute is a subclass of the persuasion dialogue, where the thesis to be proved by each student must be proved exclusively from the commitments of the other student, according to the rules of inference.

Persuasion dialogue is a situation where the goal of each participant is to convince the other participant of the acceptability of a specific proposition, based on premises that the other participant either already has accepted or can be gotten to accept. One special type of persuasion dialogue is the dispute, where the thesis to be proven of one student is the opposite (negation) of the other student. Characteristically, the parliamentary debate and the criminal trial are types of disputes.

Inquiry dialogue is a type of dialogue where the goal is to acquire further knowledge in a particular area, or on a topic. The inquiry requires proof or evidence, or the establishment of a conclusion based on given evidence which is accepted in a field of inquiry at the original situation. The inquiry is characteristically a hierarchical and orderly search procedure, similar to what Aristotle called a demonstration, where the premises are needed to be better known or established than the conclusion which is to be proved (D'Angelo, 1997).

Negotiation dialogue is a kind of interest-based bargaining, where the goal is for the arguer to maximize his agenda, to get the "best deal" possible. Unlike the first two types of dialogue, negotiation has little to do with the weighing of logical reasoning to establish knowledge or to justify ideals, values, or convictions. In negotiation, the disputants contest for scarce goods, and concessions or trade-offs agreed to be bargaining exchanges, not propositions held to be true, provable, or plausible.

Any dialogue begins with some difference of opinion which leads to the creation of an issue to be resolved or discussed. The issue is a particular set of propositions which sets the agenda for discussion by formulating what is to be proved or disproved by each student. The problem should ideally be set in the opening stages of a discussion, because the setting of the problem determines, at the global level, which arguments are relevant and which can be ruled as irrelevant. Eemeren and Grootendorst (1983) differentiate an initial confrontation phase of dialogue where the participants define the goals of the discussion and clarify or agree on some of the rules. These agreements or clarifications, as far as they are known by a third-party critic of the discourse, serve to define the context of dialogue. Such global rules, of five kinds, pertaining to the whole dialogue as an ordered sequence: 
Two Sides: In the basic case of dialogue, there must be two participants, each of whom represents one side of the issue to be discussed. Conventionally, these two participants are called the Proponent and the Respondent.

Moves: $A$ dialogue is an ordered sequence of moves. Normally, each participant takes a turn in making a move. So, a dialogue is a sequence of pairs of moves where the pair has input from each side. Normally, a pair is a question and a reply to that question.

Commitments: Attached to each side is a set of propositions called a commitment-set. At each move, depending on the rules of dialogue, propositions are inserted into this set or removed from it.

Procedural Rules: The rules of dialogue define the permissible moves, the types of locutions involved in a move, the regulation of commitment insertion and deletion, and sequences of moves that fulfill the goals of the dialogue.

Goals of Dialogue: $A$ dialogue must have a specific goal or criterion of success. The goal states which sequences of moves, according to the procedural rules, count as a successful culmination or resolution of the dialogue.

Students are encouraged to share explicit elements of their own culture, both providing legitimacy to cultural diversity and incorporating these cultural understandings into ontological and epistemological exploration using critical dialogue (Cho, 2010). For the teacher and the students, the use of a problemposing focus-one that combines course content to the real-world struggles of students-helps to highlight and challenge hidden cultural and historical societal dynamics that create imbalances of power (Edwards, 2010), eventually, providing new ways for students to claim authority for their own experience (Cho, 2010).

Innovative, problem-centred, and meaning-constructive ways of teaching should be adopted by educators who want to achieve teaching goals (Wilhem \& Firmin, 2009). Griffin, Brown and Warren (2012) remarked that through critical dialogue, the classroom is transformed from a place for the dispensation of knowledge into a place where knowledge is disassembled, approached from multiple and missing perspectives, and reassembled in ways that create both critical understanding and paths for social change. Although not everyone may gain equally from participation, critical dialogue offers the opportunity for each participant to become aware of previously hidden power struggles, more understanding of those with whom they interact, and able to work toward a more just future.

The philosophy of Economics in the Nigerian Educational system is to present it as a subject that has relevance in everyday life and could prepare graduates for an entrepreneurial career in future (NERDC, 2008). Economics as a subject is a peculiar aspect of reality (Van Myk, 2007). Hanson (1979) posited that economics is the social science that studies the economic aspect of reality. Economics is a science, and like any other science, it involves a systematic effort to determine uniform patterns of behaviour. Economics has the methodological procedure, systematic analysis and testable theories. These patterns of behaviour are used to describe what is happening, to predict what could happen, and to help policymakers develop the most suitable policy (Van Myk, 2007). Van Myk further asserted that experts accept that Economics is a science in its right and there is no doubt regarding the core analytical content of Economics. The scientific knowledge of Economics is embodied in the form of economic concepts, principles, theories and models (Barkley, 2008).

The teaching of Economics as a school subject focuses on specific overall outcomes which are to acquaint the learners with the understanding of the national economy, basic economic problems, participate in economic matters and interpret statistical data and make informed decisions (Bisschoff, et al, 1992). Horton, Weidenaar and Gregory (1996) further asserted the main objective of economics education is to promote the understanding of the world. Barring this understanding, individuals are 
frequently confused and unable to identify, analyze and decode successfully the economic aspects inherent in the world.

One of the objectives of the new curriculum on Economics is to enable students to contribute intelligently to discourse on economic reforms and development as they affect the generality of Nigeria. This demands an upward level of performance from Economics students. However, the conventional method of teaching, which is the preference of most Economics teachers allow students to simply obtain information from the teacher without building their engagement level with the subject being taught (Boud \& Feletti, 1999). As a result, there are agitations for teachers to be dynamic with their instructional method to encourage the development of students' generic skills (Bennett, Dunne, \& Carre, 1999). But, teachers are finding it difficult to adopt a new instructional strategy to achieve set objectives. Hence, it was of interest to see whether critical dialogue strategy (as alternative teaching and learning approach to the conventional method) could be adapted to aid students' understanding of Economics.

The main purpose of this study was to determine the difference in the performance of students taught with critical dialogue and conventional instructional strategy in Economics. Specifically, the following purposes are expected to guide this study as it seeks to find out:

i. the difference in the performance of students taught with critical dialogue based on gender.

The following research hypotheses were used to guide this study.

$\mathrm{H}_{01}$ : There is no significant difference in the performance of students taught using critical dialogue and conventional instructional strategies in Economics.

$\mathrm{H}_{02}$ : There is no significant difference in the performance of male and female students exposed to critical dialogue instructional strategy.

\section{METHOD}

The study was a quasi-experimental design which employed pre-test and post-test design. The population of this study covered all senior secondary school students in Abeokuta. Two secondary schools were purposively sampled after which one school was subjected to an experimental group whose students were exposed to critical dialogue and the other school was subjected to control group and taught with the conventional method. The experimental group had an intact class of 35 students while the control group also had an intact class of 38 students (conventional) making a total of 73 students. Open-ended questions on the topics taught in Economics was used as an instrument to determine students' performance before and after the treatment. This instrument contained 8 questions drawn from 4 topics (Market structure, Industrialization, Agriculture and Fiscal Policy) which were selected from SSS II Second Term Economics Syllabus to ensure its content validity while its reliability coefficient 0.63 was obtained through a pilot test conducted outside the sampled schools.

Given the permission from the appropriate authorities of the two sampled schools, the field-work of the study lasted for a period ten (10) weeks. The $1^{\text {st }}$ week was spent in obtaining the pre-test data from both the experimental and control schools (groups) the open-ended questions on the topics the respondents would be taught. The eight subsequent weeks were expended in giving treatments to the sampled schools by exposing the experimental school to critical dialogue teaching method and the control school to the conventional method. The $10^{\text {th }}$ week was spent in obtaining the post-test data from both the experimental and control schools (groups) using open-ended questions based on the topics taught. Data obtained were analysed using Analysis of Covariance (ANCOVA) at 0.05 level of significance. 
For the experimental group, critical dialogue instructional strategy was integrated into the lesson. Students were placed in five groups of seven students each. The following points guide the teacher while planning the lesson. Isaac (1996) Critical Dialogue Instructional Strategy was adopted for this study:

In the initial phase of the dialogue, participants are focused on trust and safety in the context or environment. This phenomenon is called instability of the environment. In this stage, participants are focused on certain parameters to which the moderator must attend. Participants in the second phase struggle with each other, both getting caught in and trying to avoid the polarization and conflict that emerge when individual's different beliefs and different assumptions are revealed. Groups at this stage search for new rules to guide them and help them through. They reflect on the meaning and the question of "whose meaning has more power here". This stage leads to the group's first efforts to suspend personal assumptions publicly and leads to the next stage.

In the third stage, participants begin to ask questions about the different ideas and polarizing beliefs and statements. Participants begin to wonder about their position and those of others. Called the phase of the inquiry, a deeper level of exchange begins to occur, leading to the fourth stage. The fourth stage is characterized by creativity in the dialogue environment. In this phase, "members begin to think generatively, and new understandings based on collective perception emerge".

The following critical dialogue instructional strategy was incorporated into the lesson plan and was reflected as the plan is being implemented. The researcher acted as a moderator by going round each group to monitor the progress made and inform the students when they are deviating from the objective of the lesson. Then, researcher reverted the class to its usual setting and calls on a student from each group to share their dialogue with the rest of the class and clears any doubts students may have.

Control group: the students in this group were exposed to eight weeks of conventional teaching method (Lecture method) i.e. the teacher assumed the position of dispensing knowledge to the learners

\section{FINDINGS}

Two null hypotheses were formulated in this study and tested at 0.05 level of significance.

$\mathbf{H}_{\mathbf{0 1}}$ : There is no significant difference in the performance of students taught using critical dialogue and conventional instructional strategies in Economics.

To test this hypothesis, Analysis of Covariance (ANCOVA) was used to test if there is a significant difference in the performance of students exposed to critical dialogue. The result of the analysis is shown in Table 1.

Table 1

Result of Analysis of Covariance on the differences between Experimental Group and Control Group

\begin{tabular}{lccrrr}
\hline Source of variance & Sum of squares & df & Mean square & F & Sig. \\
\hline Corrected model & $5841.417^{\mathrm{a}}$ & 2 & 307.443 & 5.389 & .000 \\
Intercept & 22659.807 & 1 & 22659.807 & 397.160 & .000 \\
Pretest & 4154.966 & 1 & 230.831 & 25.263 & .000 \\
Instructional Strategy & 1441.382 & 1 & 1441.382 & 4.046 \\
Error & 3023.898 & 53 & 57.055 & .000 \\
Total & 256064.000 & 73 & & \\
Corrected Total & 8865.315 & 72 & & & \\
\hline
\end{tabular}

a. $\quad$ R squared $=.659$ (Adjusted $\mathrm{R}$ squared $=.537) \mathrm{F}(1,53)=4.05$, e. $=.000$ 
ANCOVA result in Table 1 shows that there is significant difference in the performance of students taught with critical dialogue, F $(1,53=4.05, \mathrm{p}=0.000)$. Therefore, the hypothesis was rejected.

$\mathbf{H}_{\mathbf{0 2}}$ : There is no significant difference in the performance of male and female students exposed to critical dialogue instructional strategy.

To test this hypothesis, Analysis of Covariance (ANCOVA) was used to test if there is a significant difference in the performance of students exposed to critical dialogue based on gender. The result of the analysis is shown in Table 2.

Table 2

Result of Analysis of Covariance on the Posttest Scores of students exposed to critical dialogue strategy based on gender

\begin{tabular}{|c|c|c|c|c|c|}
\hline Source & Type III Sum of Squares & $\mathrm{df}$ & Mean Square & $\mathrm{F}$ & Sig. \\
\hline Corrected Model & $6901.471^{\mathrm{a}}$ & 4 & 1725.368 & 23.173 & .000 \\
\hline Intercept & 8062.812 & 1 & 8062.812 & 108.289 & .000 \\
\hline Pretest & 6801.611 & 1 & 6801.611 & 91.350 & .000 \\
\hline Critical dialogue & 1109.772 & 1 & 1109.772 & 14.905 & .000 \\
\hline Gender & 131.675 & 1 & 389.924 & 5.237 & .025 \\
\hline $\begin{array}{l}\text { Critical dialogue* } \\
\text { Gender }\end{array}$ & 169.300 & 1 & 139.361 & 2.274 & .136 \\
\hline Error & 5063.023 & 68 & 74.456 & & \\
\hline Total & 226564.000 & 73 & & & \\
\hline Corrected Total & 11964.493 & 72 & & & \\
\hline
\end{tabular}

The result of the ANCOVA as depicted in Table 7 indicated that there was no significant difference in the performance male and female students exposed to critical dialogue instructional strategy, $\mathrm{F}(1,68)$ $=2.274, \mathrm{p}=0.136$.

\section{CONCLUSION, DISCUSSION AND SUGGESTIONS}

From the observations highlighted, critical dialogue helps students to think critically, thereby using their experience in the classroom outside the school environment and vice versa. Also, the long-term benefit of critical dialogue should help students understand economics as a secondary school subject more thereby aiding them at higher levels of education and in retrospect assist to contribute intelligently to the economic discourse in the society.

Finding of this study revealed that critical dialogue instructional strategy has effect on students' academic performance in economics in Abeokuta. Therefore, the hypothesis which states that there is no significant effect on students' academic performance in economics was rejected. This is so because critical dialogue instructional strategy has been traced to action research as it brings multiple stakeholders in the classroom to work on shared problems and evidence-informed practice (Moyles, et al.,2002). Critical dialogue is more than simple self-reflection because it allows peer interactions and provides scaffolds that support and guide reflection. In the same vein, critical dialogue separates itself from conventional teaching through the openings it offers to analyze competing definitions of similar issues (Duncum, 2008). Jackson (2008) opined that by placing teachers and students in positions of agency, critical dialogue transforms traditional lessons into democratic educational experiences. 
The second finding of this study showed that there was no significant difference in the performance of students exposed to critical dialogue instructional strategy in economics in Abeokuta based on gender, therefore, the hypothesis was not rejected. In other words, critical dialogue instructional strategy does not favour male over female or vice versa. In essence, the instructional strategy is not gender-bias and accommodates the intellectual ability of all learners. This is against the findings of Olson (2002) which reported that females performed better than males' students when exposed to cooperative learning. Also, the findings disagree Aguele and Uhumniah (2008) and Khairulanuar, Nazre, Sairabanu, and Norasikin (2010) who reported gender difference in favour of male students. Furthermore, the findings are in line studies such as Kost, Pollock and Finkelstein (2009), Ajaja and Eravwoke (2010), Yusuf (2011), Oludipe (2012) and Essien (2012) which reported that gender had no influence on academic performance of students in cooperative learning. This study suggested the following:

i. Teachers should expose students to critical dialogue instructional strategy in passing out instruction in the classroom as it has been found out to improve the performance of students and also to develop students' critical-thinking skills.

ii. Colleges of Education and Faculties of Education in Nigerian Universities should incorporate critical dialogue instructional strategy in their curriculum so that prospective teachers will acquire basic skills for design and implementation of such strategies.

iii. Curriculum planners should introduce critical dialogue as an instructional strategy for enhancing utmost academic achievement in economics.

\section{REFERENCES}

Aguele, L. I. \& Uhumniah, N. V. (2008). Female participation in science, technology and mathematics (STM) education in Nigeria and national development. Journal of Social Science, 15(2), 121-126.

Ajaja, O. P. \& Eravwoke, O. U. (2010). Effects of cooperative learning strategy on junior secondary school students' achievement in integrated science. Electronic Journal of Science Education, 14(1). Retrieved from http://ejse.southwestern.edu

Barkley, P. W. (1998). Economics: The way we choose (2nd Ed). New York: Harcourt Brace.

Barth, E. M. \& Krabhe, E. C. W. (1998). From axiom to dialogue. Berlin: De Gruyter

Bennett, N., Dunne, E., \& Carre, C. (1999). Patterns of core and generic skill provision in higher education. Higher Education, 37(1), 71-93.

Bisschoff, T. T., Fourie, H. M. A., Froneman, E. M., Landey, V., Paxton, P. A., \& Smit, H. V. (1992). Teaching commercial subjects. Doornfontein: Oikospaisago Publishers.

Boud, D. \& Feletti, G. (1999). The challenge of problem-based learning (2nd Ed.), Kogan Page: London.

Cho, S. (2010). Politics of critical pedagogy and new social movements. Educational Philosophy and Theory, 42(3), 310-325.

D'Angelo, E. (1997). The teaching of critical thinking. Amsterdam: Griiner

Duncum, P. (2008). Thinking critically about critical thinking: Towards a post-critical, dialogic pedagogy for popular visual culture. International Journal of Education through Art, 4(3), 247-257.

Edwards, D. B. (2010). Critical pedagogy and democratic education: Possibilities for crosspollination. The Urban Review, 42(3), 221-242. 
Eemeren, F. H. V. \& Grootendorst, R. (1983). Speech acts in argumentative discussions. Dordrecht: Foris Publications.

Essien, I. T. (2012). The influence of multiple-choice and essay type test on gender differences in geography: A Study of Selected Senior Secondary Schools in Uyo Municipality. African Education Indices. 1(1), 64-71

Freire, P. (1990). Education for critical consciousness. New York: Continuum.

Freire, P. (2003). Pedagogy of the oppressed. New York: Continuum.

Freire, P. (2007). Daring to dream: Toward a pedagogy of the unfinished. New York: Continuum.

George, G. P. (1994). The effectiveness of cooperative learning strategies in multicultural university classrooms. Excellence in College Teaching, 5(1), 21-30.

Greitzer, F. A. (2002). Cognitive approach to student-centered e-learning, human factors and society. 46th Annual Meeting, Sept 30 - Oct 4.

Griffin, S. R., Brown, M., \& Warren, N. M. (2012). Critical education in high schools: The promise and challenges of intergroup dialogue. Equity \& Excellence in Education, 45(1), 159 - 180.

Hanson, R. (1998). Economic growth given machine intelligence. Retrieved from http://hanson.gmu.edu/aigrow.pdf

Isaacs, W. N. (2001). Toward an action theory of dialogue. International Journal of Public Administration, 24, 709-748.

Jackson, L. (2008). Dialogic pedagogy for social justice: A critical examination. Studies in Philosophy and Education, 27(2), 137-148.

Johnson, D. W., Johnson, R. T., \& Smith, K. A. (1998). Cooperative learning returns to college: What evidence is there that it works? Change: The Magazine of Higher Learning, 30(4), 26-35.

Johnson, L., \& Morris, P. (2010). Towards a framework for critical citizenship education. The Curriculum Journal, 21(1), 77-96.

Khairulanuar, S., Nazre, A. R., Sairabanu, O.K. \& Norasikin, F. (2010). Effects of training method and gender on learning 2D/3D geometry. Journal of Computers in Mathematics and Science Teaching, 29(2), $\quad 175 \quad-\quad 188 . \quad$ Chesapeake, Retrieved from http://www.editlib.org/p/33188

Kincheloe, J. L. (2007). Critical pedagogy. New York: Peter Lang.

Kost, L. E., Pollock, S. J. \& Finkelstein, N. D. (2009). Characterizing the gender gap in introductory physics. Physics Education Research, 5(1), 1-14

Leistyna, P. (1999). Presence of mind: Education and politics of deception. Boulder, CO: West View Press.

Mejia, A. (2004). The problem of knowledge imposition: Paulo Freire and critical systems thinking. Systems Research and Behavioral Science, 21(1), 63-82.

Mezirow, J. (2000). Learning to think like an adult: Core concepts in transformation theory. In M. Mezirow, Learning as transformation: Critical perspectives on a theory in progress. San Francisco: Jossey-Bass. 
Moyles, J., Adams, S., \& Musgrove, A. (2002). Using reflective dialogues as a tool for engaging with challenges of defining effective pedagogy. Early Child Development and Care, 172, 463-476.

Nigerian Educational Research and Development Council (2007). 9-year Basic Education Curriculum, Economics for Senior Secondary School SSS 1-3, NERDC Press, Lagos.

Okebukola, P.A. (1985). Effects of cooperative, competitive Individualistic laboratory interaction patterns on students' performance in biology (Unpublished Ph.D. Thesis). University of Ibadan, Nigeria.

Olson, V. E. (2002). Gender differences and the effects of cooperative learning in college level mathematics (Unpublished Ph.D. thesis) Curtin University of Technology, Perth, Western Australia.

Oludipe, D. I. (2012). Gender Difference in Nigerian Junior Secondary Students Academic Performance in Basic Science. Journal of Educational and Social Research, 2(1), 93-99.

Ormrod, J. (1995). Educational psychology: Principles and applications. Englewood, Cliffs, N.J.: Prentice-Hall.

Schein, E. (1993). On dialogue, culture, and organizational learning. Organizational Dynamics, 22, 40-51.

Stauffer, W. (2013). The effects of cooperative learning on the academic achievement, social interaction, behaviour and affect of secondary English and Social Studies students (Unpublished Master's Thesis). Evergreen State College, Evergreen.

Takeda, A., Marchel, C. \& Gaddis, R. (2002). Performing reflective practice in college education and counsellor training. Japanese Journal of Counseling Science, 35, 145-154.

Teo, R. \& Wong, A. (2000). Does problem-based learning create a better student: a reflection? A Paper presented at the 2nd Asia Pacific Conference on Problem Based Learning: Education Across Disciplines, December 4-7, Singapore.

Van Myk, M. W. (2007). The use of cooperative learning in Economics in the further education and training phase in the Free State province (Unpublished Doctoral Dissertation, Department of Curriculum Studies). University of Free State, Bloemfontein, South Africa.

Wilhelm, G. M., \& Firmin, M. W. (2009). Historical and contemporary developments in home school education. Journal of Research on Christian Education, 18, 303- 315.

Yusuf, A. (2011). Effects of cooperative instructional strategy on junior secondary students' performance in Social Studies. Retrieved from http://www.scholar.google.com/cooperative/l earning

Zakaria, E., Chin, C.L. \& Daud, Y. (2010). The effect of cooperative learning on student mathematics achievements and attitude towards mathematics. Journal of Social Sciences,6(2), 272-275. 